\title{
Centenarians and supercentenarians: a black swan. Emerging social, medical and surgical problems
}

\author{
Marco Vacante ${ }^{1}$, Velia D'Agata ${ }^{2}$, Massimo Motta' ${ }^{1}$, Giulia Malaguarnera ${ }^{3}$, Antonio Biondi', Francesco Basile ${ }^{4}$, \\ Michele Malaguarnera ${ }^{2 *}$, Caterina Gagliano ${ }^{5}$, Filippo Drago ${ }^{2}$, Salvatore Salamone ${ }^{2}$
}

From XXV National Congress of the Italian Society of Geriatric Surgery

Padova, Italy. 10-11 May 2012

\begin{abstract}
The Black Swan Theory was described by Nassim Nicholas Taleb in his book "The Black Swan". This theory refers to "high-impact, hard-to-predict, and rare events beyond the realm of normal expectations". According to Taleb's criteria, a Black Swan Event is a surprise, it has a major impact and after the fact, the event is rationalized by hindsight, as if it had been expected. For most of human history centenarians were a rare and unpredictable phenomenon. The improvements of the social-environmental conditions, of medical care, and the quality of life caused a general improvement of the health status of the population and a consequent reduction of the overall morbidity and mortality, resulting in an overall increase of life expectancy. The study of centenarians and supercentenarians had the objective to consider this black swan and to evaluate the health, welfare, social and economic consequences of this phenomenon.
\end{abstract}

\section{Introduction}

The term "Black Swan" comes from the 17th century European belief that the existence of a black swan was impossible. After a hundred years black swans were discovered in Western Australia and so the term started to indicate that a perceived impossibility may come to pass [1]. The Black Swan Theory refers to high-impact, hardto-predict, and rare events beyond the realm of normal expectations. The theory was described by Nassim Nicholas Taleb in his 2007 book "The Black Swan". Taleb regards almost all major scientific discoveries, historical events, and artistic accomplishments as "black swans" undirected and unpredicted [1]. Healthy centenarians are a living example of successful aging free from chronic diseases causing permanent injuries and from reduced mental and physical functions [2]. For most of human history centenarians were a rare and unpredictable phenomenon [3]. Although numerous studies have characterized the

\footnotetext{
* Correspondence: m.malaguarnera@email.it

${ }^{2}$ Department of Biomedical Sciences, Via S. Sofia, 87, 95123, University of Catania, Italy

Full list of author information is available at the end of the article
}

centenarian phenotype according to metabolic, endocrine, immune, physical and cognitive functions, little work has emerged that describes the health histories associated with exceptional longevity [4-7]. The improvements of the social-environmental conditions, of medical care, and the quality of life caused a general improvement of the health status of the population and a consequent reduction of the overall morbidity and mortality, resulting in an overall increase of life expectancy. Around the 1970s, the progressive decline of mortality ( $1-2 \%$ per year) in individuals over 80 years old has increased in all industrialized countries, so that the number of centenarians has augmented about 20-fold [8]. The term "supercentenarians" describes the subjects who had reached 110 years of age, in a validated manner. Their prevalence is estimated to be $0.3-0.5 \%$ of the centenarians [9]. Supercentenarians should be considered as exceptional individuals having a particularly efficient network, able for exceptional performances to slow down the numerous pathological conditions determining the aging process, and stimulating the factors resulting in resistance against diseases, increasing this way the survival [10]. 


\section{Factors that influence the longevity}

Many studies suggested that some factors are important to longevity in centenarians: 1 ) heredity, role of specific genes and family history [11] 2) general health and lifestyle, i.e. weight, diet, amount of physical exercise, smoking habits $[12,13] 3)$ education level [14] 4) personality $[15,16]$. The largest population of centenarians are widowed women [17]. The Okinawa Centenarians Study (OCS) has shown several different factors that have contributed to the large number of centenarians there. These factors are: 1 ) a diet based mainly on grains, fish and vegetables instead of meat, eggs, and dairy products; 2) low-stress lifestyles, compared to the mainland inhabitants of Japan; 3) caring community and active work until an older age than the average age in other countries; 5) a strong role of spirituality, with involvement in spiritual matters and prayer that ease the mind of stress and problems [18-20]. Human longevity is due to genetics, age, sex, ethnicity and environment of the study population. [21-23]. Whether prolonged caloric restriction (CR) increases average or maximum lifespan or promotes a more youthful physiology in humans at advanced ages is not yet known. However, available epidemiological evidence indicates that CR may already have contributed to an extension of average and maximum life span in older Okinawans and appears to have lowered risk for age associated chronic diseases in other human populations [24].

\section{General conditions of centenarians}

Centenarians display extremely variable clinical conditions. On the one hand, there are frail individuals among them with polypathologies, being an expression of the terminal deterioration related to the progressive increase of the medium life span. On the other hand, there are subjects without particular disease conditions or cognitive disorders. Some of them present, however, signs of the advanced aging process, such as hypoacusia, visual disorders, limited locomotor capacities, etc. $[25,26]$. A consortium of 20 university departments of geriatrics and gerontology conducted the Italian Multicentric Study on Centenarians (IMUSCE), in order to assess the socio-economic, clinical and biological conditions of Italian centenarians. According to the IMUSCE criteria, based on psychophysical status and autonomy, centenarians can be classified in three groups as follows: Group A: centenarians in good health status; Group B: centenarians in an intermediate health status. Group C: centenarians in bad health status. Group A represented $20.0 \%$ of the total pool, Group B amounted to $33.4 \%$, and the Group C was $46.6 \%$. The centenarians of Group A presented normal activities of daily living (ADL) values, and $47.9 \%$ of them were autosufficient in all functions; $5.7 \%$ of them were independent in all instrumental activities of daily living (IADL) items. These data confirm that the centenarians of Group A are free of invalidating chronic diseases, are autonomous, maintain good physical and cognitive capacities, however, have not maintained any social or productive activities. Therefore, they cannot be considered as prototypes of successful aging [26].

\section{Supercentenarians}

The supercentenarians display an elevated percentual occurrence of alterations which do not have a deterministic role in the survival: (cataract, osteoporosis, bone fractures, etc.), and a low prevalence of more significant, chronic degenerative pathologies. Generally they reach 100 years of age in good health, and only after 105 years of age start to manifest age-dependent alterations with high variability [9]. Usually their death cause is not correlated to the typical pathologies of aged people, such as cancer, stroke, myocardial infarction, etc. [22,27]. The decreased prevalence of various pathologies widely documented in the centenarians, as compared to the elderly, seems to be present also in the supercentenarians, compared to the centenarians. Even the dementia of various clinical aspects, which is the only disease condition more frequent in the elderly than in the centenarians [28] seems to be of lower prevalence in the supercentenarians, as compared to the centenarians [9].

\section{Immunity and centenarians}

Ageing of the immune system relates to both innate and adaptive immunity although the innate one is regarded to be better preserved than adaptive one [29-31]. The agerelated alterations of adaptive immunity include a decline of naive $\mathrm{T}$ lymphocytes and accumulation of memory/ effector $\mathrm{T}$ cells, reduction in the number of $\mathrm{B}$ cells, upregulation of the inflammatory responses and dysregulation of the Th1/Th2 system. The increased number of Natural Killer (NK) cells with well-preserved cytotoxic function is a characteristic feature of the innate part of ageing immune system [32]. The process of successful ageing, (i.e. ageing in good psychophysical conditions) [33] is immunologically characterized by preserved lymphoproliferative responses and NK cytotoxic activity as well as conserved antigen presentation [34]. Healthy centenarians show normal number of $\mathrm{T}$ lymphocytes, increased production of immunoglobulins, lack of organspecific autoantibodies, well preserved NK activity and retained proliferative capability of $\mathrm{T}$ lymphocytes [35]. The remodelling of the immune system occurring with age is capable of creating a hostile environment for the growth of cancer cells in centenarians [36]. In fact an age-dependent increase of CD8+ CD28 - T cells having a high cytotoxic capacity, both in percentage and absolute number, has been found in elderly people and centenarians $[37,38]$. Moreover, an increased number and percentage of NK cells (CD16+, CD56+, CD57+) has 
been found in centenarians with the highest NK function and number of NK cells have preserved endocrine conditions and muscle mass $[39,40]$. Thus the increase with the age of cells with NK features could cause a prevailing of the innate immunity in the oldest old, which might create an unfavourable environment for neoplastic growth [41-44].

\section{Hormonal status in centenarians}

It is well known that physiological changes in the neuroendocrine system may be related to the process of aging. A study revealed several differences in the neuroendocrine and metabolic status of centenarians, compared with other age groups, including the lowest serum concentrations of leptin, insulin and T3, and the highest values for prolactin. $\mathrm{LH}$ and FSH levels were comparable with those in the elderly and postmenopausal groups, but they were significantly higher than in younger subjects. $\mathrm{GH}$ concentrations in centenarians were lower than in younger women. It has been also demonstrated that BMI in centenarian subjects does not differ significantly from BMI of younger subjects but it is lower than that found in early elderly subjects [45]. Several studies in humans have shown that longevity is associated with a significant improvement in glucose handling - mainly, a rise in insulin sensitivity and a decline in plasma insulin-like growth factor I levels [46]. Moreover Paolisso et al. demonstrated that centenarians compared with aged subjects had a preserved glucose tolerance and insulin action despite to the decline in insulin action due to advancing age [47].As regards thyroid activity, contrasting results have been revealed. In fact it has been showed an age-related decline of the TSH levels and a significant increase of the reverse $\mathrm{T}_{3}\left(\mathrm{rT}_{3}\right)$ concentrations in centenarians by comparison to old controls. These findings may be related to an age-dependent reduction of the 5 -deiodinase activity [48]. Other studies showed that the distribution of serum TSH shifts progressively to higher concentrations with age, appearing to be a continuum that extends even to people with exceptional longevity. The inverse correlation between TSH and FT4 in this study populations suggests that changes in negative feedback may contribute to exceptional longevity [49].

\section{Energy, carnitine and antioxidants}

L-carnitine and its short-chain esters facilitate long-chain fatty acid transport across the inner mitochondrial membrane for $\beta$-oxidation. It thereby promotes energy availability and prevents toxic accumulation of long-chain fatty acids [50,51]. Acetyl-L-carnitine (ALC) is an ester of L-carnitine, a trimethylated aminoacid; it is synthesized in the central nervous system (CNS), liver, and kidney via the action of ALC transferase and stored in skeletal muscle, both in the free form and as an ester with acetyl groups
[52]. ALC concentration is age and gender dependent. ALC controls the transport of long-chain fatty acids in mitochondria and then their $\beta$-oxidation, and it ensures the minimum necessary level of acetyl-coenzyme A required for energetic cellular metabolism [53]. ALC is the most abundant L-carnitine ester in the nervous system, being fundamental for lipid metabolism and polyunsaturated fatty acids synthesis in neuronal membrane. It is also able to improve neuronal metabolism by increasing the use of glucose and eliminating oxidative metabolites and to enhance the activities of electron transport chain enzymes [54-56]. Caloric restriction, low levels of oxidative stress and changes in glucose handling seem to be the most compelling factors relating longevity and metabolism. Caloric restriction has been shown to reduce body temperature, improve insulin sensitivity (by lowering fasting plasma glucose and insulin levels and improving insulin action), lower fasting plasma free insulin-like growth factor I (IGF-I) and dehydroepiandrosterone (DHEA) levels and improve thyroid activity. Together, these actions result in two main effects: lowering energy production in the mitochondrial complex and minimizing DNA damage and thus genomic instability. With regard to energy production in the mitochondrial complex, an ad libitum diet is associated with enhanced production of reactive oxygen substances (ROSs) that activate several cascade mechanisms resulting in impairment of enzyme activity. In contrast, caloric restriction lowers mitochondrial activity, which decreases the production of ROSs, leading to a secondary improvement in intracellular metabolism. Cellular aging is slowed by decreasing the production of ROSs, which leads to reduced DNA damage [57]. The principal target of ALC's action is mitochondrial DNA, on which it exerts an antioxidant effect and stimulates mitochondrial DNA synthesis [58]. Moreover ALC supplementation may reduced significantly both physical and mental fatigue and improved physical activity and cognitive status [59]. Various mechanism can explain the therapeutic effect of ALC, such as the beneficial effects of ALC on mitochondrial alterations and on the progressive impairment of neurotransmission, the correction on deficits of cellular energy supply. Carnitine and its derivative, ALC affect other cellular functions, including maintenance of key proteins and lipids of the mitochondria at sufficient levels, proper membrane orientation and maximum energy production [60].

\section{Cardiovascular risk factors and oxidative stress in centenarians}

Several studies have shown that centenarians have better cardiovascular risk profiles compared to younger old people. Some reports have revealed that cardiovascular diseases (i.e. hypertension, diabetes, angina and/or myocardial infarction) are less common in centenarians respect to 70 and 80 years old persons [61]. Centenarians 
have high levels of the natural antioxidants vitamins A and E [62] that may be protective from atherosclerosis. But they present enhanced coagulation enzyme activity, elevated plasma fibrinogen and homocysteine levels, which represent thrombotic risk factors for middle-aged individuals [63-66]. Moreover centenarians present elevated levels of IL-18, which is a proinflammatory cytokine that appears to be involved in atherosclerosis [67]. Gangemi et al demonstrated the apparent paradox of elevated serum IL-18 with no vascular signs in centenarians can be explained by the presence of high IL-18 binding protein levels (a protein that neutralizes the activity of IL-18) in these subjects [68]. A study showed that indices of oxidative stress (reaction products of malondialdehyde with thiobarbituric acid (TBARS) and lipid hydroperoxides (LPO), were lower in centenarians than in aged subjects. In contrast, reduced/oxidized glutathione ratio (GSH/ GSSG) and plasma concentrations of antioxidant defenses (plasma vitamin E and C) were more elevated in centenarians than in aged subjects [69]. A study by Rabini et al showed that there is an age-associated trend in the platelet membrane concentrations of a biomarker of oxidative stress (MDA), but centenarians showed platelet membrane concentrations of MDA lower than elderly subjects and similar to the levels found in an adult group. These difference is associated with a decreased platelet activation and therefore might exert a protective role against cardiovascular accidents, as platelet activation is a key event in the initiation and progression of arteriosclerosis [70]. As regards the lipids analysis in centenarian populations, contrasting results have been revealed. There are findings about decreased or increased values of total cholesterol, LDL- and HDL-cholesterol, triglycerides, ApoB100, and ApoA1. As regards the serum levels of lipoprotein(a), increased or unchanged values have been observed [71-73] Total cholesterol decreased with advancing age, but highdensity lipoprotein maintained at high levels, consistent with a previously reported lipoprotein phenotype of exceptional longevity in centenarians [74]. Receputo et al. observed noted that total cholesterol values in a group of male centenarians were within the normal range and were significantly lower than in elderly male subjects [75]. These data support the protective role of low total cholesterol values also with regard to longevity [76]. Even if blood pressure progressively increases with age [77], Gareri et al. have not found it in centenarians [78]. The lesser frequency of hypertension in centenarians certainly depends on genetic and constitutional factors, but also their style of life and alimentary habits (decreased sodium intake, increase of calcium and potassium intake) could be determinant $[79,80]$. The extraordinary longevity of centenarians can not be explained even if hypertension, that is a risk factor for cardiovascular and cerebrovascular morbidity and mortality, is present for all the ages of life [78].

\section{Cancer and longevity}

Centenarians appear to "outlive" the risks for many of those conditions that are common causes of death for those who die in their 70s, 80s and 90s, such as cancer and myocardial infarction [81]. The analysis of demographic data indicates that cancer incidence and mortality show a levelling off around the age of 85-90 years, and suggests that oldest old people and centenarians are protected from cancer onset and progression [82]. Accordingly, studies on autopsy records revealed that long-lived people and centenarians are characterised by a lower than expected incidence, metastatic rate and mortality for cancer [83,84]. Moreover an autoptic study performed on 140 centenarians, has revealed the presence of various types of cancer in $16.3 \%$, as compared to the average elderly showing $39.0 \%$, and there was a lower aggressivity of metastases, too (24.0\% vs. $55.0 \%)$ [85]. The complex relationship between the change of apoptosis susceptibility with age and cancer prevalence in the oldest old can predict that gene products and polymorphisms of genes are involved in apoptosis [86]. A particular attention deserves the relationship between apoptosis, its age-related changes, and cancer susceptibility in the oldest old [87]. ApoJ is a gene which appears to play an important role in aging, apoptosis and cancer but whose role is still unclear [88]. In cancer cells, this gene confers cytoprotection by inhibiting apoptosis, although there are reports indicating a pro-apoptotic function of ApoJ in other tumor-derived cell lines [89] In recent years the extensive genotypisation of centenarians led to study polymorphisms which are claimed to be able to affect individual's cancer susceptibility, namely those located in the anti-oncogene p53, in the oncogene HRAS1, in asset of genes involved in carcinogens metabolism, i.e. cytochrome P450 oxidases (CYP) and glutathione transferases (GST), in a gene whose mutations are risk factor for breast cancer (BRCA1) and in a gene whose activity is a potential risk factor for prostate cancer (SRD5A2) [41] Nevertheless it is difficult to interpret the net difference in the prevalence of cancer in extreme longevity: in the Okinawa Centenarian Study (OCS) [22], cancer is absent, while in the New England Centenarian Study (NECS) [27], it is present in $25 \%$ of the supercentenarians, however, all of them were previously treated, and none of them were active. This is a condition which justifies the presence of cancer in the supercentenarians. Some of centenarians had been affected by cancer in their life, but they survived, even though during an historical period when cancer treatment was not as developed as in the present days $[90,91]$. Thus is reasonable to conclude that centenarians are people endowed with a peculiar resistance to cancer [41] The relationship between polymorphism associated with cancer susceptibility and human longevity is complex and the studies so 
far performed provided insights on some mechanisms involved in human longevity. At the moment the role of the immunosenescence on cancer incidence is an extremely debated argument [92]. It has been suggested that the immunosenescence is not an inevitable and progressive decline of all immune functions, but rather the result of a continuous remodelling process in which several functions are reduced, others increased, while others remain unchanged [93]. Studies of the immune system of centenarians, spotlighted that one of the main factors of longevity may be represented by well functioning immune system which allows the prevention of the main age-related pathologies including cancer, as death from cancer may decline at very old age. In elderly subjects practicing regularly moderate exercise training, some aspects of immunosenescence are attenuated or improved, both innate immunity and acquired immunity, as the reduction of memory cells and the increase of naïve $\mathrm{T}$ cells $[94,95]$ increase further the production of primary antibody response [96].

\section{Conclusion}

Life expectancy has dramatically increased over the last few centuries of human history and it continues to increase. Before about $2000 \mathrm{BC}$, the number of births per year was under 1 million; until roughly 1000 AD annual global births ran at less than 10 million; only since 1970 have more than 100 million babies been added to the human population each year [97]. If the chance of surviving to age 100 is about 1 in 20 million when life expectancy is 20 and about 1 in 80,000 when life expectancy is 40 (a level not reached in Western Europe until the early 19 th century), then centenarians must have been exceedingly rare in most countries before the modern era. The identification of a Black Swan Event, basing on Taleb's criteria, includes that the event is a surprise, the event has a major impact and after the fact, the event is rationalized by hindsight, as if it had been expected [1]. The Black Swan event is isolated and unpredictable. One naturally tends to give a retrospective justification of his appearance to make it less random than it actually is. Unless there is some secret of longevity that has enabled some humans to transcend the death rates that governed the fate of nearly all their contemporaries, most accounts of centenarians in earlier centuries must be inaccurate [98]. In Italy the number of centenarians has risen from 49 in 1921 to 1304 in 1981 , to 1660 in 1990, to 4000 in December 1995 [99,100]. The growth in the number of centenarians has garnered significant attention over the past 20 or so years. One study reported Medicare data indicating that, in 2000 , there were 32,920 centenarians and that, of these, $0.3 \%$ were age 110 and older [101]. Furthermore it is estimated that seven in 1,000 people born at the turn of the last century lived to become centenarians and that one in 100,000 lived to be 110 or older [102]. A better understanding of the biochemical and neuroendocrine determinant of aging has put interventions on a somewhat more solid scientific foundation to combat a few of the deleterious consequences of aging. Many studies are concerned with elucidating the regulatory mechanisms of aging at the cellular level and we expect that they will also have practical implications that translate into real therapeutic interventions in the coming decades [103]. The centenarians can still be heterogeneous enough to warrant careful phenotyping for the purposes of discovering different potential genetic and environmental correlates of exceptional longevity. In addition, there may be distinctive genetic and environmental interactions involved in the exceptional longevity of men versus women. According to the U.S. Department of Census, the number of centenarians could cross the 4 million mark by 2050 [104] In the US, the rise in health care expenditures associated with the rapid increase in the elderly population will likely place additional pressures on the Medicaid and Medicare programs, as well as private insurers, to control health care costs. Efforts to control costs will likely have a negative impact on both the supply of and demand for health workers. Nevertheless, the growth of centenarians and even more of supercentenarians, deserves a detailed evaluation as regards the enormous social, economic and health impacts. The high impact of longer lifespans has consisted in the last years in a gradual alteration of the way individuals want to spend their time during lives, thus leading to drastic revision of education, health, employment, retirement and other policies. The study of centenarians and supercentenarians had the objective to consider this black swan to better understand the health, welfare, social and economic consequences of this phenomenon.

\section{Acknowledgements}

MMalaguarnera has been supported by the International PhD programme in Neurosciences, University of Catania, Italy.

This article has been published as part of BMC Surgeny Volume 12 Supplement 1 , 2012: Selected articles from the XXV National Congress of the Italian Society of Geriatric Surgery. The full contents of the supplement are available online at http://www.biomedcentral.com/bmcsurg/supplements/12/S1.

\section{Author details}

Department of Senescence, Urological and Neurological Sciences, Cannizzaro Hospital Via Messina 829, 95125, University of Catania, Italy. ${ }^{2}$ Department of Biomedical Sciences, Via S. Sofia, 87, 95123, University of Catania, Italy. ${ }^{3}$ International PhD programme in Neurosciences, University of Catania, Italy. ${ }^{4}$ Department of General Surgery, Section of General Surgery and Oncology, Vittorio Emanuele Hospital, Via Plebiscito 628 University of Catania, 95123 Catania, Italy. ${ }^{5}$ Department of Ophtalmology, Via S. Sofia 78, 95123, University of Catania, Italy.

\section{Authors' contributions}

MV, MM: conception and design, drafting the manuscript, given final approval of the version to be published; VDG, MM, GM, CG, FD: drafting the manuscript, given final approval of the version to be published; FD, SS, $A B$, FB: critical revision, given final approval of the version to be published. 


\section{Competing interests}

The authors declare that they have no competing interests.

Published: 15 November 2012

\section{References}

1. Taleb NN: The Black Swan: The Impact of the Highly Improbable. Random House Ed; 2007.

2. Terry DF, Sebastiani P, Andersen SL, Perls TT: Disentangling the roles of disability and morbidity in survival to exceptional old age. Arch Intern Med 2008, 168:277-83.

3. Vaupel JW, Jeune B: The emergence and proliferation of centenarians. In Exceptional longevity: From prehistory to present. Monographs on population aging. Volume 2. Odense, Denmark: Odense University Press;Jeune B. \& Vaupel JW 1995.

4. Malaguarnera M, Pistone G, Motta M: The elderly and quality of life. $\mathrm{Br}$ Med J 1995, 311:1136.

5. Mariotti S, Sansoni P, Barbesino G, Caturegli P, Monti D, Cossarizza A, et al: Thyroid and other organ-specific autoantibodies in healthy centenarians. Lancet 1992, 339:1506-8.

6. Bürkle A, Caselli G, Franceschi C, Mariani E, Sansoni P, Santoni A, et al: Pathophysiology of ageing longevity and age related diseases. Immun Ageing 2007, 4:4.

7. Franceschi C, Monti D, Sansoni P, Cossarizza A: The immunology of exceptional individuals: the lesson of centenarians. Immunol Today 1995, 16:12-6.

8. Christensen K, Doblhammer G, Rau R, Vaupel JW: Ageing populations: the challenges ahead. Lancet 2009, 374:1196-208.

9. Motta M, Cardillo E, Vacante M, Malaguarnera M: Supercentenarians: the oldest people in the world. Indian J Med Res 2010, 131:4-6.

10. Andersen SL, Sebastiani P, Dworkis DA, Feldman L, Perls TT: Health span approximates life span among many supercentenarians: compression of morbidity at the approximate limit of life span. J Gerontol A Biol Sci Med Sci 2012, 67:395-405.

11. De Benedictis G, Tan Q, Jeune B, Christensen K, Ukraintseva SV, Bonafè M, et al: Recent advances in human gene-longevity association studies. Mech Ageing Dev 2001, 122:909-20.

12. Willcox BJ, Willcox DC, Todoriki H, Fujiyoshi A, Yano K, He Q, et al: Caloric restriction, the traditional Okinawan diet, and healthy aging: the diet of the world's longest-lived people and its potential impact on morbidity and life span. Ann N Y Acad Sci 2007, 1114:434-55.

13. Cappellani A, Di Vita M, Zanghi A, Cavallaro A, Piccolo G, Veroux M, et al: Diet, obesity and breast cancer: an update. Front Biosci (Schol Ed) 2012, 4:90-108.

14. Perls TT, Morris JN, Ooi WL, Lipsitz LA: The relationship between age, gender and cognitive performance in the very old: the effect of selective survival. J Am Geriatr Soc 1993, 41:1193-201.

15. Adams ER, Nolan VG, Andersen SL, Perls TT, Terry DF: Centenarian offspring: start healthier and stay healthier. J Am Geriatr Soc 2008 , 56:2089-92.

16. Givens JL, Frederick M, Silverman L, Anderson S, Senville J, Silver M, et al: Personality traits of centenarians' offspring. J Am Geriatr Soc 2009, 57:683-5.

17. Carey JR, Judge DS: Principles of biodemography with special reference to human longevity. Population: An English Selection 2001, 13:9-40.

18. Santrock J: Physical Development and Biological Aging. In: A Topical Approach to Life-Span Development. New York: McGraw-Hill Companies, Inc:Mike Ryan, Michael J. Sugarman, Maureen Spada, and Emily Pecora 2008:129-132.

19. Suzuki M, Willcox BJ, Willcox DC: Implications from and for food cultures for cardiovascular disease: longevity. Asia Pac J Clin Nutr 2001, 10:165-171.

20. Rajpathak SN, Liu Y, Ben-David O, Reddy S, Atzmon G, Crandall J, et al: Lifestyle factors of people with exceptional longevity. J Am Geriatr Soc 2011, 59:1509-12.

21. Motta M, Malaguarnera M, Ferrari E, Mauro VN, Ferrucci L, Rapisarda R, et al: Genealogy of centenarians and their relatives: a study of 12 families. Arch Gerontol Geriatr 2007, 45:97-102.

22. Willcox DC, Willcox BJ, Wang NC, He Q, Rosenbaum M, Suzuki M: Life at the extreme limit: phenotypic characteristics of supercentenarians in Okinawa. J Gerontol A Biol Sci Med Sci 2008, 63:1201-8.
23. Sanabe E, Ashitomi I, Suzuki M: Social and medical survey of centenarians. Okinawa J Pub Health 1977, 9:98-106.

24. Willcox DC, Willcox BJ, Todoriki H, Curb JD, Suzuki M: Caloric restriction and human longevity: what can we learn from the Okinawans? Biogerontology 2006, 7:173-77.

25. Motta M, Maugeri D, Malaguarnera M, Italian Multicenter Study on Centenarians (IMUSCE): Centenarians in good health conditions. Arch Gerontol Geriatr 2002, 8:209-17.

26. Motta M, Bennati E, Ferlito L, Malaguarnera M, Motta L, Italian Multicenter Study on Centenarians (IMUSCE): Successful aging in centenarians: myths and reality. Arch Gerontol Geriatr 2005, 40:241-51.

27. Schoenhofen EA, Wyszynski DF, Andersen S, Pennington J, Young R, Terry DF, et al: Characteristics of 32 supercentenarians. J Am Geriatr Soc 2006, 54:1237-40.

28. Italian Multicentric Study on Centenarians (IMUSCE study Group; coordinators: Motta L, Franceschi C): Centenarians in Italy: epidemiological and clinical-biological findings. In Lecture at $96^{\circ}$ Congress of Italian Society of Internal Medicine (SIMI), Rome Pozzi 1995.

29. Malaguarnera L, Ferlito L, Di Mauro S, Imbesi RM, Scalia G, Malaguarnera M: Immunosenescence and cancer: a review. Arch Gerontol Geriatr 2001, 32:77-93.

30. Malaguarnera $\mathrm{L}$, Cristaldi E, Vinci M, Malaguarnera M: The role of exercise on the innate immunity of the elderly. Eur Rev Aging Phys Act 2008, 5:43-49.

31. Malaguarnera L, Cristaldi E, Lipari H, Malaguarnera M: Acquired immunity: immunosenescence and physical activity. Eur Rev Aging Phys Act 2008, 5:61-68.

32. Sansoni $P$, Vescovini $R$, Fagnoni F, Biasini $C$, Zanni F, Zanlari $L$, et al: The immune system in extreme longevity. Exp Gerontol 2008, 43:61-5.

33. Rowe JW, Kahn RL: Human aging: usual and successful. Science 1987, 237:143-9.

34. DelaRosa O, Pawelec G, Peralbo E, Wikby A, Mariani E, Mocchegiani E, et al: Immunological biomarkers of ageing in man: changes in both innate and adaptive immunity are associated with health and longevity. Biogerontology 2006, 7:471-81.

35. Franceschi C, Monti D, Barbieri D, Salvioli S, Grassilli E, Capri M, et al: Successful immunosenescence and the remodelling of immune responses with ageing. Nephrol Dial Transplant 1996, 11:18-25.

36. Bonafè M, Barbi C, Storci G, Salvioli S, Capri M, Olivieri F, et al: What studies on human longevity tell us about the risk for cancer in the oldest old: data and hypotheses on the genetics and immunology of centenarians. Exp Gerontol 2002, 37:1263-71.

37. Fagnoni FF, Vescovini R, Mazzola M, Bologna G, Nigro E, Lavagetto G, et al: Expansion of cytotoxic CD8+ CD28- T cells in healthy ageing people, including centenarians. Immunology 1996, 88:501-7.

38. Nociari MM, Telford W, Russo C: Postthymic development of CD28-CD8+ T cell subset: age-associated expansion and shift from memory to naive phenotype. J Immunol 1999, 162:3327-35.

39. Mariani E, Ravaglia G, Forti P, Meneghetti A, Tarozzi A, Maioli F, et al: Vitamin $D$, thyroid hormones and muscle mass influence natural killer (NK) innate immunity in healthy nonagenarians and centenarians. Clin Exp Immunol 1999, 116:19-27.

40. Miyaji C, Watanabe $H$, Toma H, Akisaka M, Tomiyama K, Sato Y, et al: Functional alteration of granulocytes, NK cells, and natural killer T cells in centenarians. Hum Immunol 2000, 61:908-16.

41. Bonafè M, Valensin S, Gianni W, Marigliano V, Franceschi C: The unexpected contribution of immunosenescence to the leveling off of cancer incidence and mortality in the oldest old. Crit Rev Oncol Hematol 2001, 39:227-33.

42. Malaguarnera G, Leggio F, Vacante M, Motta M, Giordano M, Biondi A, et al: Probiotics in the gastrointestinal diseases of the elderly. J Nutr Health Aging 2012, 16:402-10.

43. Palmeri M, Misiano G, Malaquarnera M, Forte Gl, Vaccarino L, Milano S, et al Cytokine serum profile in a group of Sicilian nonagenarians. J Immunoassay Immunochem 2012, 33:82-90.

44. Malaguarnera M, Vacante M, Bertino G, Neri S, Malaguarnera M, Gargante MP, et al: The supplementation of acetyl-L-carnitine decreases fatigue and increases quality of life in patients with hepatitis $C$ treated with pegylated interferon- $\mathrm{a} 2 \mathrm{~b}$ plus ribavirin. J Interferon Cytokine Res 2011, 31:653-9. 
45. Baranowska B, Bik W, Baranowska-Bik A, Wolinska-Witort E, Szybinska A, Martynska $L$, et al: Neuroendocrine control of metabolic homeostasis in Polish centenarians. J Physiol Pharmacol 2006, 57:55-61.

46. Barbieri M, Paolisso G, Kimura M, Gardner JP, Boccardi V, Papa M, et al: Higher circulating levels of IGF-1 are associated with longer leukocyte telomere length in healthy subjects. Mech Ageing Dev 2009, 130:771-6.

47. Paolisso G, Gambardella A, Ammendola S, D'Amore A, Balbi V, Varricchio M, et al: Glucose tolerance and insulin action in healty centenarians. Am J Physiol 1996, 270:E890-4.

48. Magri F, Muzzoni B, Cravello L, Fioravanti M, Busconi L, Camozzi D, et al: Thyroid function in physiological aging and in centenarians: possible relationships with some nutritional markers. Metabolism 2002, 51:105-9.

49. Atzmon G, Barzilai N, Hollowell JG, Surks MI, Gabriely I: Extreme longevity is associated with increased serum thyrotropin. J Clin Endocrinol Metab 2009, 94:1251-4.

50. Brecher P: The interaction of long-chain acyl CoA with membranes. Mol Cell Biochem 1983, 57:3-15.

51. Malaguarnera M, Pistone G, Receputo G, Rapisarda R, Tomasello FB, Motta $\mathrm{M}$, et al: Serum carnitine levels in centenarians. Clin Drug Invest 1999, 17:321-7.

52. Bianchi G, Vitali G, Caraceni A, Ravaglia S, Capri G, Cundari S, et al: Symptomatic and neurophysiological responses of paclitaxel- or cisplatin-induced neuropathy to oral acetyl-L-carnitine. Eur J Cancer 2005, 41:1746-50.

53. Famularo G, De Simone C: A new era for carnitine? Immunol Today 1995, 16:211-3.

54. Herzmann C, Johnson MA, Youle M: Long-term effect of acetyl-L-carnitine for antiretroviral toxic neuropathy. HIV Clin Trials 2005, 6:344-50.

55. Galvano F, Li Volti G, Malaguarnera M, Avitabile T, Antic T, Vacante M, et al: Effects of simvastatin and carnitine versus simvastatin on lipoprotein(a) and apoprotein(a) in type 2 diabetes mellitus. Expert Opin Pharmacother 2009, 10:1875-82.

56. Malaguarnera M, Vacante M, Motta M, Malaguarnera M, Li Volti G, Galvano F: Effect of L-carnitine on the size of low-density lipoprotein particles in type 2 diabetes mellitus patients treated with simvastatin. Metabolism 2009, 58:1618-23.

57. Heilbronn LK, de Jonge L, Frisard MI, DeLany JP, Larson-Meyer DE, Rood J, et al: Pennington CALERIE Team. Effect of 6-month calorie restriction on biomarkers of longevity, metabolic adaptation, and oxidative stress in overweight individuals: a randomized controlled trial. JAMA 2006, 295:1539-1548.

58. Famularo G, Moretti S, Marcellini S, Trinchieri V, Tzantzoglou S, Santini G, et al: Acetyl-carnitine deficiency in AIDS patients with neurotoxicity on treatment with antiretroviral nucleoside analogues. AIDS 1997, 11:185-90.

59. Malaguarnera M, Gargante MP, Cristaldi E, Colonna V, Messano M, Koverech $A$, et al: Acetyl L-carnitine (ALC) treatment in elderly patients with fatigue. Arch Gerontol Geriatr 2008, 46:181-90.

60. Iossa S, Mollica MP, Lionetti L, Crescenzo R, Botta M, Barletta A, et al: Acetyl-L-carnitine supplementation differently influences nutrient partitioning, serum leptin concentration and skeletal muscle mitochondrial respiration in young and old rats. J. Nutr 2002, 132:636-642.

61. Galioto A, Dominguez LJ, Pineo A, Ferlisi A, Putignano E, Belvedere M, et al: Cardiovascular risk factors in centenarians. Exp Gerontol 2008, 43:106-13.

62. Mecocci P, Polidori MC, Troiano L, Cherubini A, Cecchetti R, Pini G, et al: Plasma antioxidants and longevity: a study on healthy centenarians. Free Radic Biol Med 2000, 28:1243-8.

63. Mari D, Mannucci PM, Coppola R, Bottasso B, Bauer KA, Rosenberg RD: Hypercoagulability in centenarians; the paradox of successful aging. Blood 1995, 85:3144-3149.

64. Mutus B, Rabini RA, Franceschi C, Paolisso G, Rizzo MR, Ragno E, et al: Cellular resistance to homocysteine: a key for longevity. Atherosclerosis 2000, 152:527-8.

65. Malaguarnera M, Pistone G, Motta M, Vinci E, Oreste G, Avellone G, et al: Elevated plasma total homocysteine in centenarians. Clin Chem Lab Med 2004, 42:307-10.

66. Malaguarnera M, Ruello P, Rizzo M, Receputo G, Rapisarda R, Restuccia N, et al: Lipoprotein(a) levels in centenarians. Arch Gerontol Geriatr 1996, 22:385-8.

67. Dinarello CA: Interleukin-18, a proinflammatory cytokine. Eur Cytokine Netw 2000, 11:483-6.
68. Gangemi S, Basile G, Merendino RA, Minciullo PL, Novick D, Rubinstein M, et al: Increased circulating Interleukin-18 levels in centenarians with no signs of vascular disease: another paradox of longevity? Exp Gerontol 2003, 38:669-72.

69. Paolisso G, Tagliamonte MR, Rizzo MR, Manzella D, Gambardella A Varricchio M: Oxidative stress and advancing age: results in healthy centenarians. J Am Geriatr Soc 1998, 46:833-8.

70. Rabini RA, Vignini A, Martarelli D, Nanetti L, Salvolini E, Rizzo MR, et al: Evidence for reduction of pro-atherosclerotic properties in platelets from healthy centenarians. Exp Gerontol 2003, 38:367-71.

71. Malaguarnera M, Giugno I, Ruello P, Rizzo M, Panebianco MP, Pistone G, et al: Lipid profile variations in a group of healthy elderly and centenarians. Eur Rev Med Pharmacol Sci 1998, 2:75-9.

72. Toshaki I: Standard results of various physical examinations of centenarians in Japan from Japanese centenarians. In Medical Research for the Final Stage of Human Aging. Editorial and Publishing Office of Japanese Centenarians, Aichi, Japan;H. Tauchi, T. Sato and T. Watanabe 1999:54-68.

73. Uccello M, Malaguarnera G, Pelligra EM, Biondi A, Basile F, Motta M: Lipoprotein(a) as a potential marker of residual liver function in hepatocellular carcinoma. Indian J Med Paediatr Oncol 2011, 32:71-5.

74. Barzilai N, Atzmon G, Schechter C, Schaefer EJ, Cupples AL, Lipton R, et al: Unique lipoprotein phenotype and genotype associated with exceptional longevity. JAMA 2003, 290:2030-2040.

75. Nikka M, Heikkein J: High density lipoprotein cholesterol and longevity. Age Ageing 1990, 19:119-124.

76. Gordon T, Kannel WB, Hjortland MC, McNamara PM: Menopause and coronary heart disease. The Framingham Study. Ann Intern Med 1978, 89:157-61.

77. Harlan WR, Hull AL, Schmouder RL, Landis JR, Larkin FA, Thompson FE: High blood pressure in older Americans. The First National Health and Nutrition Examination Survey. Hypertension 1984, 6:802-9.

78. Gareri P, Lacava R, Rossi MG, Iorio C, Galasso MA, Pansini L, et al: Hypertension in a group of centenarians. Arch Gerontol Geriatr 1996, 22:373-376.

79. Piccinni G, Testini M, Angrisano A, Lissidini G, Gurrado A, Memeo R, et al: Nutritional support in patients with acute pancreatitis. Front Biosci (Elite Ed) 2012, 4:1999-2006.

80. Berretta M, Lleshi A, Fisichella R, Berretta S, Basile F, Li Volti G, et al: The role of nutrition in the development of esophageal cancer: what do we know? Front Biosci (Elite Ed) 2012, 4:351-7.

81. Gessert CE, Elliott BA, Haller IV: Dying of old age: an examination of death certificates of Minnesota centenarians. J Am Geriatr Soc 2002, 50:1561-5.

82. Piantanelli L: Cancer and aging: from the kinetics of biological parameters to the kinetics of cancer incidence and mortality. Ann N Y Acad Sci 1988, 521:99-109.

83. Stanta G, Campagner L, Cavallieri F, Giarelli L: Cancer of the oldest old. What we have learned from autopsy studies. Clin Geriatr Med 1997, 13:55-68.

84. Miyaishi O, Ando F, Matsuzawa K, Kanawa R, Isobe K: Cancer incidence in old age. Mech Ageing Dev 2000, 117:47-55.

85. Motta M, Bennati E, Vacante M, Stanta G, Cardillo E, Malaguarnera M, Giarelli L: Autopsy reports in extreme longevity. Arch Gerontol Geriatr 2010, 50:48-50.

86. Ragusa M, Statello L, Maugeri M, Majorana A, Barbagallo D, Salito L, et al: Specific alterations of the microRNA transcriptome and global network structure in colorectal cancer after treatment with MAPK/ERK inhibitors. J Mol Med (Berl) 2012.

87. Monti D, Salvioli S, Capri M, Malorni W, Straface E, Cossarizza A, et al: Decreased susceptibility to oxidative stress-induced apoptosis of peripheral blood mononuclear cells from healthy elderly and centenarians. Mech Ageing Dev 2000, 121:239-50.

88. Bettuzzi S, Troiano L, Davalli P, Troppa F, Ingletti MC, Grasselli E, et al: In vivo accumulation of sulphated glycoprotein-2 (SGP-2) mRNA in rat Thymocytes upon dexamethasone-induced cell death. Biochem. Biophys. Res. Commun 1991, 175:810-815.

89. Trougakos IP, Gonos ES: Clusterin/Apolipoprotein J in human ageing and cancer. Int. J. Biochem. Cell Biol 2002, 34:1430-1448.

90. Franceschi C, Motta L, Valensin S, Rapisarda R, Franzone A, Berardelli M, et al: Do men and women follow different trajectories to reach extreme 
longevity? In Aging (Milano). Volume 12. Italian Multicenter Study on Centenarians (IMUSCE); 2000:77-84.

91. Franceschi C, Valensin S, Bonafè M, Paolisso G, Yashin Al, Monti D, De Benedictis G: The network and the remodeling theories of aging: historical background and new perspectives. Exp Gerontol 2000, 35:879-96.

92. Malaguarnera L, Cristaldi E, Malaguarnera M: The role of immunity in elderly cancer. Crit Rev Oncol Hematol 2010, 74:40-60.

93. Franceschi C, Monti D, Barbieri D, Grassilli E, Troiano L, Salvioli S, et al: Immunosenescence in humans: deterioration or remodelling? Int Rev Immunol 1995, 12:57-74.

94. Weksler ME, Szabo P: The effect of age on the B-cell repertoire. J Clin Immunol 2000, 20:240-9.

95. Woods JA, Ceddia MA, Wolters BW, Evans JK, Lu Q, McAuley E: Effects of 6 months of moderate aerobic exercise training on immune function in the elderly. Mech Ageing Dev 1999, 109:1-19.

96. Smith TP, Kennedy SL, Fleshner M: Influence of age and physical activity on the primary in vivo antibody and $\mathrm{T}$ cell-mediated responses in men. J Appl Physiol 2004, 97:491-8.

97. McEvedy C, Jones R: Atlas of World Population History. Allen Lane, London; 1978

98. Thoms WJ: Human Longevity, Its Facts and Its Fictions. John Murray, London; 1873.

99. Antonini FM, Mannucci M: How can we apply the study of centenarians in gerontology today? Giornale di Gerontologia 1991, 39:525-532.

100. ILSA Group (The Italian Longitudinal Study on Aging Working Group): Prevalence of chronic diseases in older Italians: comparing self-reported and clinical diagnoses. Int. J. Epidemiol 1997, 26:995-1002.

101. Kestenbaum B, Ferguson RB: Number of Centenarians in the United States, January 1, 1990, January 1, 2000 and January 1, 2010. Based on Improved Medicare Data. Paper presented at Society of Actuaries Orlando, $\mathrm{FL}_{\text {; }}$ 2005 [on-line]. Available at http://library.soa.org/library-pdf/m-li05-1_XXVI.pdf Accessed April 13, 2011.

102. Robine JM, Vaupel JW: Supercentenarians: Slower ageing individuals or senile elderly? Exp Gerontol 2001, 36:915-930.

103. Coles LS: Demography of human supercentenarians. J Gerontol A Biol SCi Med Sci 2004, 59:579-586.

104. Day J: Population projections of the United States by age sex race and Hispanic origin: 1995-2050. US Bureau of Census Current Population Reports Washington DC: US Government Printing Office; 1996, 25-1130.

doi:10.1186/1471-2482-12-S1-S36

Cite this article as: Vacante et al:: Centenarians and supercentenarians: a black swan. Emerging social, medical and surgical problems. BMC

Surgery 2012 12(Suppl 1):S36.

\section{Submit your next manuscript to BioMed Central and take full advantage of:}

- Convenient online submission

- Thorough peer review

- No space constraints or color figure charges

- Immediate publication on acceptance

- Inclusion in PubMed, CAS, Scopus and Google Scholar

- Research which is freely available for redistribution 